\title{
MULTIMODAL METAPHORIC CONSTRUAL OF ECOLOGY IN ENGLISH DOCUMENTARIES
}

\author{
Yana Vermenych \\ Postgraduate Student, V. N. Karazin Kharkiv National University, Ukraine \\ e-mail: yanavermenich@gmail.com, orcid.org/0000-0002-2179-3906
}

\section{Summary}

In this article, I consider multimodal instantiations of conceptual metaphors with the referent ECOLOGY selected from English documentary films that address ecological issues. In this discourse environment, conceptual metaphors can be instantiated in different semiotic modes, namely, verbal, visual, and / or aural. Metaphors under consideration are treated as multimodal construals that emerge in the process of interaction of the meaning of the linguistic expression with the context, an important aspect of which is the interrelation of the semiotic modes mentioned above. It is shown that cognitive techniques of modifying conceptual metaphors, such as elaboration, extending, questioning, and combining (Lakoff \& Turner, 1989: 67-70; Kövecses, 2010a: 53-55), which used to be considered as a feature of poetic discourse, are characteristic of ecological filmic discourse as well. These techniques serve to enrich the content of conventional conceptual metaphors. This effect is enhanced by the interaction of different semiotic modes in the process of meaning-making, which can result in the emergence of rich conceptual metaphors that capture the complex nature of ecological objects and phenomena. The effects of multimodal conceptual metaphors in documentary films demonstrate variety: the visual mode can endow conceptual metaphors instantiated verbally with new features; the visual mode can intensify the effect of verbally manifested metaphors by highlighting certain attributes of the metaphorically related concepts; the aural mode can enhance the emotive metaphoric entailments or question the appropriateness of the metaphor.

Keywords: combining, elaboration, emergence, extending, multimodal conceptual metaphor, questioning, semiotic mode (verbal, visual, aural).

\section{DOI: https://doi.org/10.23856/3815}

\section{Introduction}

This article offers an analysis of conceptual metaphors in English documentaries addressing ecological problems. The study focuses on the multimodal instantiations of the metaphors, namely, those manifested in verbal, visual and / or aural semiotic modes.

Nowadays, the world community is getting increasingly concerned about ecological problems: climate change, global warming, air, water, and land pollution, waste disposal, etc. Quite a number of intergovernmental, governmental, and non-governmental organizations address these issues worldwide, nationally or locally. The Intergovernmental Panel on Climate Change (IPCC), which is one of the most influential global organizations, headed by the former Vice President of the United States Albert Arnold (Al) Gore, was awarded the Nobel Peace Prize for their efforts "to build up and disseminate greater knowledge about man-made climate change, and to lay the foundations for the measures that are needed to counteract such change" (https://www.nobelprize.org/prizes/peace/2007/summary/). Today, despite considerable advancement in this direction, the issue of raising people's ecological awareness remains highly relevant. 
One of the instruments of attracting people's attention to urgent ecological problems are documentary films, which is one of the reasons why they have been chosen as the source of empirical data for this research. Films of this genre abound in ecological concepts, some of which are quite difficult to capture. This is why filmmakers who work in this genre find conceptual metaphors quite useful.

Theoretically, the article departs from conceptual metaphor theory (Lakoff \& Johnson, 1980, 1999) and moves on to the view of conceptual metaphor as an emergent phenomenon (Sanford, 2012; Kövecses, 2015). It extends the emergentist view of metaphor by taking into consideration the possibility of its multimodal instantiation (Forceville and Urios-Aparisi, 2009).

By extrapolating Lakoff and Turner's findings that concern poetic language (Lakoff \& Turner, 1989) onto filmic discourse, this article aims to reveal how metaphors with the referent ECOLOGY emerge in the process of interaction of different semiotic modes. In order to achieve this aim, the following tasks have been set forth: to identify multimodal conceptual metaphors which belong to the domain of ecology in the documentaries under consideration; to bring to light the cognitive techniques of construing their meaning; to elicit the effect of combining different semiotic modes in the process of creating multimodal metaphors.

The leading contention of this article is that the cognitive techniques of elaboration, extending, questioning, and combining, which are traditionally regarded as a specific feature of poetic language, are characteristic of filmic discourse as well, documentary films on ecology in particular. Multimodal instantiations of cognitive metaphors formed with the help of these techniques serve to produce a number of specific effects upon the viewer, which cumulately contribute to raising the viewer's awareness of urgent ecological issues.

Structurally, the article consists of five parts: (1) introduction, (2) theoretical background, (3) results, (4) discussion and (5) conclusion. The theoretical part, which follows this introduction, presents the key concepts of conceptual metaphor theory, multimodal metaphor theory and emergentist theory of metaphor. It is followed by the presentation of results and then comes the discussion. The conclusion summarizes the findings and outlines prospects for further research.

\section{Theoretical background}

Theorized by George Lakoff and Mark Johnson, the term 'conceptual metaphor' refers to understanding one domain of experience (which is called the target) in terms of another (the source) (Lakoff \& Johnson, 1980: 5). Since conceptual metaphor is, in the first place, an instrument of thinking, and not a rhetorical device, it is quite natural to assume that it can be expressed not only with the help of verbal means. As emphasized by Ch. Forceville (Forceville, 2009: 20), conceptual metaphors can be instantiated in non-verbally as well. Metaphors which involve concepts manifested by signs of different semiotic systems are called multimodal.

This term is derivative from the term 'mode', which refers to an important concept of multimodal linguistics and semiotics; hence, it merits special consideration. Currently, there is no unity of opinion about the content of the term 'mode' (see Forceville 2006 for discussion). Researchers single out such modes as written and spoken language, gesture, visual image, music, etc. In order to describe multimodal metaphors in English documentaries on ecology, I adopt the following systematics: the verbal mode (written vs. spoken), the visual mode (static vs. dynamic images), the aural mode (the sound vs. music).

The "classical" conceptual metaphor theory, which views linguistic metaphors as surface manifestations of deep conceptual metaphors, has been criticized for its top-down approach 
by present-day researchers (Kövecses, 2015; Sanford, 2012). However, as Kövecses rightfully maintains, " $<\ldots>$ there does not seem to be a specific device in the mind responsible for producing and comprehending metaphors; instead, metaphors emerge" (Kövecses, 2015: 147). Thus, I side with the scholars who believe that individual metaphors are best understood as arising from the language in use (Kövecses, 2015: 147; Sanford, 2012: 357). Such view on conceptual metaphor allows combining the top-down approach with the bottom-up line of attack, considering conceptual metaphor both as a process and a product (Kövecses, 2015: 147). Hence, the emergentist view of metaphor seems to be natural and justifiable.

The emergentist approach to the study of conceptual metaphor shifts the focus on how we match two different concepts, i.e. which factors influence this process. Kövecses considers the following types of contextual factors: (1) the immediate physical setting, (2) what we know about the major entities participating in the discourse, (3) the immediate cultural context, (4) the immediate social setting, and (5) the immediate linguistic context itself (Kövecses, 2010b: 659-661). I would like to point out that each of these types can be detailed further, for example, the cognitive context, which is listed second in Kövecses' classification, can be static or dynamic. I focus attention on the latter, namely, on cognitive techniques that can be used in discourse to modify the content of conceptual metaphors: elaboration, extension, questioning, and combining, which were considered by Lakoff and Turner in their analysis of poetic language (Lakoff \& Turner, 1989). However, the usage of these techniques, as it follows from my data, is not limited to poetic discourse.

\section{Results}

The analysis of multimodal instantiations of conceptual metaphors in ecological filmic discourse has revealed that conceptual techniques of extending, elaboration, combining, and questioning are characteristic of this type of discourse, alongside with the poetic one. These cognitive techniques are enacted not only verbally, but also with the help of other semiotic means. Thus, in the filmic discourse under study, different configurations of verbal, visual and aural modi contribute to the process of metaphoric construal. They are considered below according to the type of conceptual technique in the following order: extending, elaboration, combining, and questioning.

In extending, "a conventional conceptual metaphor associated with certain conventionalized linguistic expressions is expressed by new linguistic means based on introducing a new conceptual element in the source domain" (Kövecses, 2010a: 53). Extending is illustrated below by a fragment taken from the documentary series 'The Broken', Episode Four 'Recycling Sham' (2019), which addresses the problem of plastic pollution. The main message of the episode is refutation of the idea that recycling plastic can solve the problem of plastic pollution. It is shown to be a false promise of plastic industry given to people in order to continue producing more plastic and earning more money. Plastic industry is presented as an enemy in the conceptual metaphor INDUSTRY is AN ENEMY that underlies the episode under consideration and is typical for ecologically oriented discourse.

The main mode of instantiating this metaphor in the fragment is verbal (the spoken variety). The conceptual metaphor INDUSTRY is AN ENEMY is expressed in a novel way: $\underline{W e}$ 're up against some of the most well-funded, ruthless, cut-throat industries on the planet. And they are actively trashing the planet. The phrasal verb to be up against, which is defined as "to be having or likely to have serious problems or difficulties" (Cambridge Dictionary), implies an inimical force which is given shape by personification (the adjectives ruthless and cut-throat 
denote attributes of a CRUEL ENEMY). The novelty of this extended metaphor derives from the element that is unusual, hard to predict: the enemy's aggression is directed against the planet on the whole (trashing the planet), not against individuals. Thus, unconventional language use activates an 'unused' element of the source (Kövecses, 2010a: 53), construing the metaphor as INDUSTRY is A CRUEL ENEMY OF THE PLANET.

The verbal mode has its visual counterpart - the image of the Exxon Mobil plant (Fig. 1), one of the world's biggest multinational oil and gas corporations. The plant is shown in twilight, which extends the metaphor further. Twilight is the time between day and night, between light and darkness, or metaphorically, between THE GOOD and THE EVIL. Thus, showing a plastic plant from a distance (a metonymic representation of danger) in twilight amounts to giving the spectator a peek of EVIL and DANGER. The disturbing background music also adds to creating the frightening atmosphere.

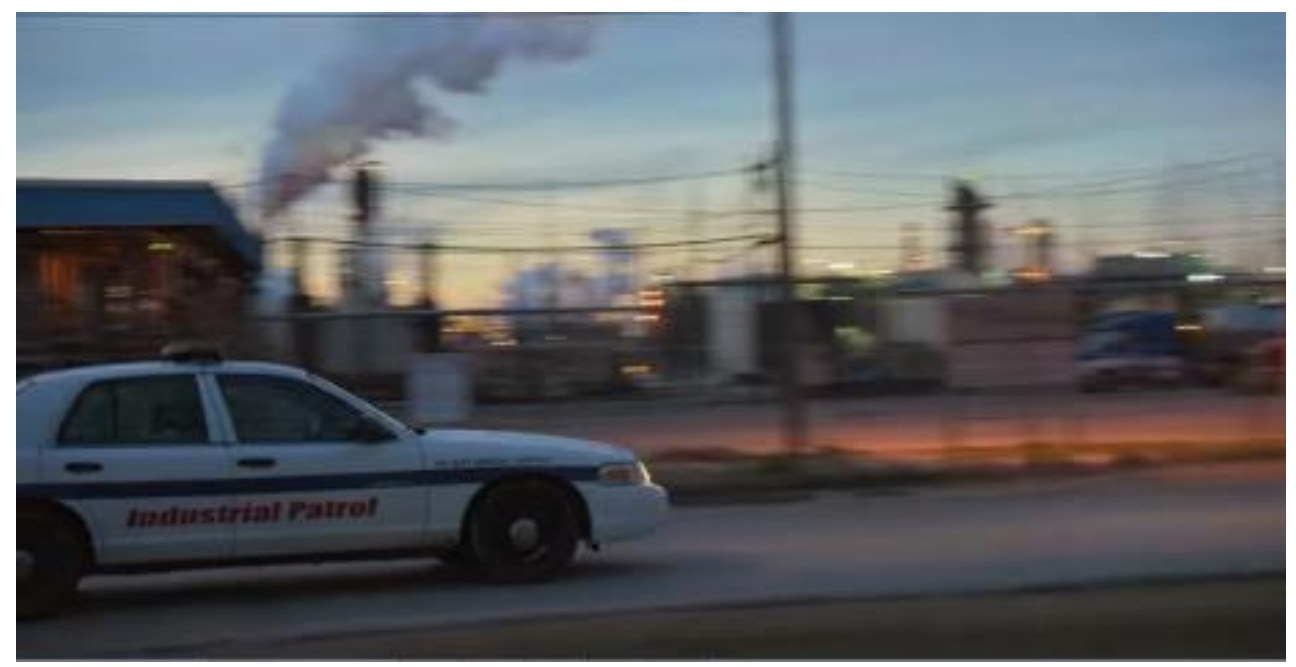

Fig. 1. Visual instantiation of the metaphor INDUSTRY is AN ENEMY

Thus, the combination of three semiotic modes - verbal, visual, and aural - extends the metaphor INDUSTRY is AN ENEMY into PLASTIC INDUSTRY is A DANGEROUS, CRUEL, EVIL ENEMY OF THE PLANET.

In the process of elaboration, an already existing element of the source domain is captured in a new and unconventional way (Kövecses, 2010a: 53). Part 3 of the documentary series 'Inside Bill's brain: decoding Bill Gates' (2019) covers his efforts to solve the problem of global warming, in particular to find a new and eco-friendly source of energy. According to Bill Gates and his team, this source is nuclear power. However, after a few massive disasters on nuclear power plants, such as Chernobyl and Fukushima, people associate nuclear energy with a powerful force which is rather dangerous. In the episode under consideration, this idea is rendered with the help of multimodal conceptual metaphor NUCLEAR ENERGY is A POWERFUL FORCE.

The metaphor builds on the conventional view of nuclear power as a dangerous and destructive force. The narrator claims this explicitly: The bomb forever seared the word 'nuclear' in our minds as a force that is destructive. And deadly. The visual mode explains why nuclear power is so frightening by presenting dramatic consequences of its misuse: numerous nuclear explosions, a black-and-white image of a boy going bold. The words bomb and destructive, 
together with the visuals, activate a larger frame of the concept, including people's painful experience of dealing with nuclear power. Further words elaborate the metaphor, drawing the viewer's attention to other characteristics of the source domain POWERFUL FORCE: But what if the thing that terrifies us could actually save us? When a neutron is shot into an atom, it creates a chain reaction and a massive amount of heat. That heat can generate steam that powers a turbine and makes electricity. All without emitting any CO2. ... So the hard part of nuclear is to make sure that, no matter what, those nuclear materials are not getting out. This verbal passage explicates that nuclear power can be eco-friendly.

Simultaneously with the verbal mode, the visual mode elaborates the metaphor (Fig. 2). Explosions become smaller, more numerous, and go from real ones to schematic. Then they appear in one small frame, symbolizing nuclear power plant where the energy is controlled. There is an image of a pipe conducting electricity from this small frame to the image of the globe. When electricity reaches the globe, it lightens up. This visual image illustrates the beneficial potential of atomic energy. This way, the conceptual metaphor NUCLEAR ENERGY is A POWERFUL DESTRUCTIVE FORCE is elaborated into NUCLEAR ENERGY is A POWERFUL BENEFICIAL ECO-FRIENDLY FORCE.

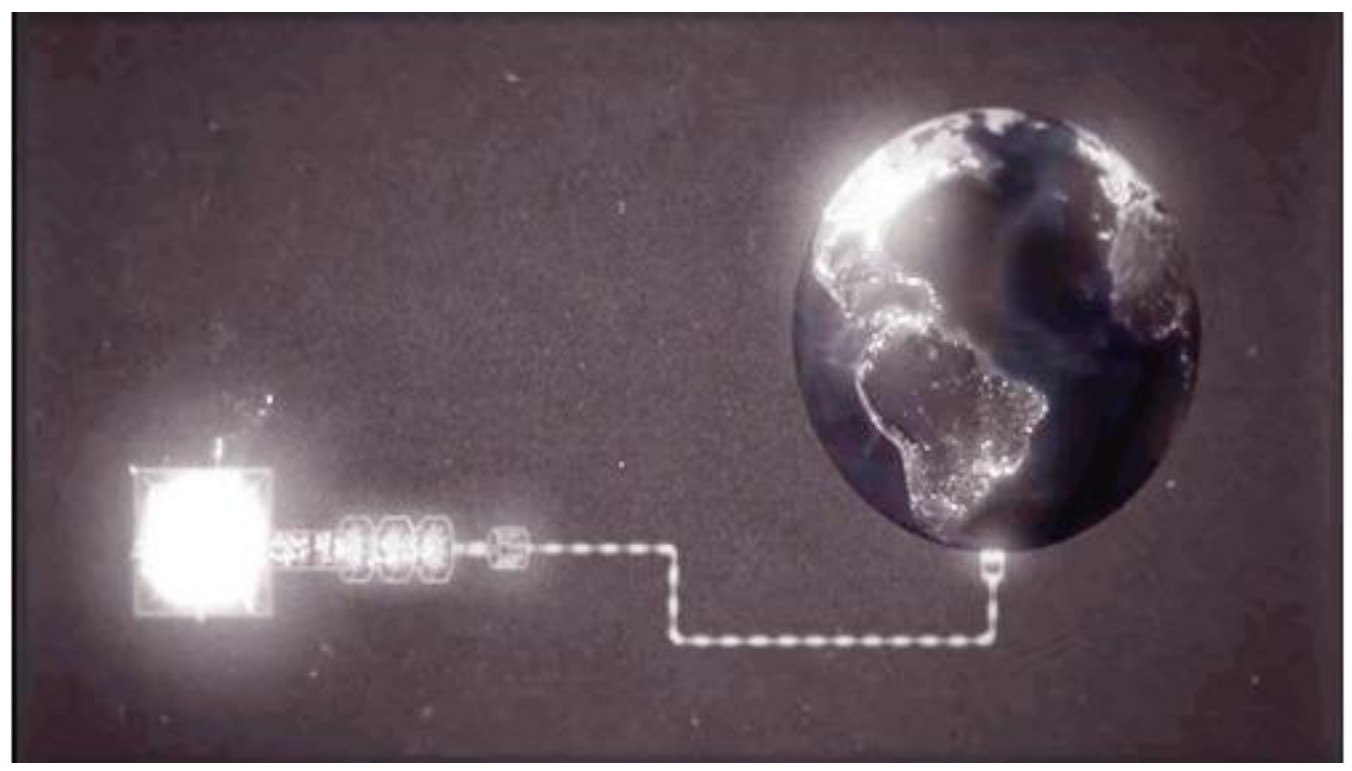

Fig. 2. Visual elaboration of the metaphor NUCLEAR ENERGY is A POWERFUL FORCE

The process of combining, characterized by Kövecses as "the most powerful mechanism to go beyond our everyday conceptual system" (Kövecses, 2010a : 55), uses "the materials of everyday conventional thought" (ibid.), joining them in a multitude of different ways. It is illustrated by a fragment from a documentary film on the problem of global warming 'Six degrees could change the world' (2008). In the fragment, two metaphors are combined to characterize the domain GLOBAL WARMING. It is enacted verbally and visually. The verbal mode of metaphor instantiation is found in the following passage: We have signs of very great changes occurring on the planet. Everything happens so fast. Our planet is at the crossroads. 
Global warming isn't out of control. But it soon could be. The warning signs are all around us. This is the challenge of climate change. The visual mode metonymically provides tell-tale signs of global warming: a bear stranded on an ice floe in the open sea, which is suggestive of melting ice caps; a burning fire truck on the road where everything is seen in the red light, which is indicative of wild fires; a few other natural disasters provoked by global warming - a storm, flood, hurricane.

The first metaphoric expression (Our planet is at the crossroads) is underpinned with the image-schema PATH, specified in the metaphor LIFE is A JOURNEY. This metaphor is first extended into CIVILIZATIONAL DEVELOPMENT OF HUMANKIND is A JOURNEY. Further, the attention is focused on a specific part of the JOURNEY, i.e. the crucial point (THE CROSSROADS) when the traveler (HUMANKIND) is to make a choice: to persist in his ruinous practices or to turn to beneficial ones. The message of the extended metaphor CIVILIZATIONAL DEVELOPMENT OF HUMANKIND is A JOURNEY, further extended into HUMANKIND is AT THE CROSSROADS, is that the global warming is real, we can see its threatening signs, but the situation is still manageable if people choose the right road.

The second metaphor is instantiated in the phrase the challenge of climate change. The concept CLIMATE CHANGE, which is a metonymic indication of GLOBAL WARMING, is characterized by referring to the source domain CHALLENGE, which implies a difficult task that humanity faces. Combining the metaphors HUMANKIND is AT THE CROSSROADS and GLOBAL WARMING is A CHALLENGE, one can easily recognize the contours of the situation of risk (Ushchyna, 2020: 78). Thus, the message that is rendered metaphorically by combining two metaphors is as follows: the wrong choice of humankind puts its future at risk.

In questioning, the appropriateness of common metaphors is called in question (Kövecses, 2010a: 54). To illustrate it, I consider another example from the documentary 'The Broken. Recycling Sham'. In our everyday life, we use quite a lot of plastic in its various forms; we are used to it and cannot imagine our life without it. In the episode, this idea is rendered by the conceptual metaphor PLASTICS are A MARVEL. The narration goes as follows: Plastics are essential to the modern world. $<\ldots>$ They are a marvel of modern life and convenience: strong, flexible and cheap. As you can produce it relatively cheaply, you can mold it into thousands of different things. Plastic packaging has huge benefits in terms of protection of food, cosmetics. The narration is accompanied by numerous images depicting things of everyday use that are made of plastic. Thus, the verbal and visual modes both instantiate the conceptual metaphor PLASTICS are A MARVEL. However, the background music, quick and disturbing, suggests that something is wrong, questioning the appropriateness of the metaphor.

Further narration continues the line of questioning, resulting in a new metaphor: PLASTIC is A MAN-MADE ENEMY. The verbal narration goes like this: But the problem with plastics is that they never really go away. Plastic is durable. $<\ldots>$ There are also serious concerns about plastic's impact on our health, from the way it's made to how we use and dispose of it. $<\ldots>$ Why and how something so embedded in our daily lives has become such a huge problem for the world? To answer that question, we need to look deep into the roots of our relationship to plastic itself. How we created and molded it, but even more, how it has come to mold us. The visual mode shows piles of plastic waste, which is a metonymic image of plastic pollution, and the aural mode continues creating a disturbing atmosphere. So the message rendered metaphorically is as follows: we created plastic, we molded it in different shapes and we use it in our everyday life, however, piles of plastic are getting bigger and bigger, we cannot control it anymore, so it is getting more powerful and dangerous for our health and life, it is becoming our enemy. 


\section{Discussion}

Metaphor is an emergent phenomenon, a contextual construct. Individual metaphors emerge in discourse for speakers / readers / viewers as metaphorical tokens. In this study, I analyze conceptual metaphors that function in documentaries on ecological issues. Due to the specific nature of filmic discourse, these conceptual metaphors can be instantiated in different semiotic modes: verbal, visual, and / or aural. Thus, I consider conceptual metaphors as multimodal construals that emerge in a synergy of different semiotic modes.

In English documentaries on ecological issues, conceptual metaphors often emerge as a result of 'enlivening' conventional conceptual metaphors, modifying their content. In filmic discourse under analysis, this is achieved by using the cognitive techniques of extending, elaboration, combining, and questioning. The animating effect is enhanced by the synergy of the verbal, visual, and aural semiotic modes.

The conceptual metaphor INDUSTRY is AN ENEMY is extended verbally and visually. The verbal manifestation of the metaphor highlights novel elements in the source domain by the following words: ruthless, cut-throat industries, trashing the planet. The visual representation of the oil and gas corporation in twilight activates another unused conceptual element EVIL. At the same time, the aural mode intensifies the frightening atmosphere. The combination of modes adds new features to the source concept ENEMY: DANGEROUS, POWERFUL, CRUEL, EVIL ENEMY OF THE PLANET.

Visual and verbal modes can go together and elaborate metaphors, as shown in the metaphor NUCLEAR ENERGY is A POWERFUL FORCE. The main elaboration happens through the visual mode, which goes from real nuclear explosions to the schematic idea of an energy source that provides energy for the whole planet, thus shifting the focus from the negative aspect of the source domain POWERFUL FORCE, which is destructive and deadly, to the positive one, where 'powerful' means 'able to provide plenty of energy'. The verbal mode supports this feature and elaborates another feature, being eco-friendly.

Combination of metaphors can be enacted verbally and visually. The metaphors HUMANKIND is AT THE CROSSROADS and GLOBAL WARMING is A CHALLENGE are instantiated in verbal mode, while the visual mode metonymically depicts the telltale signs of global warming. The visual image illustrates the target GLOBAL WARMING, making it more vivid. This results in creating a new meaning from the combination of metaphors enacted in the verbal and visual modes.

Finally, the aural mode can serve the purpose of questioning as demonstrated by questioning the metaphor PLASTICS are A MARVEL (Recycling Sham, 2019). In this example, verbal and visual modes act together in conceptualizing plastics as a marvel of the modern world. However, the disturbing background music, nothing like a melody normally associated with a marvel, creates the negative tonality and makes the spectator doubt the appropriateness of the idea. The doubt is supported by further verbal and visual narration, uncovering the true metaphor PLASTIC is A MAN-MADE ENEMY.

\section{Conclusion}

Ecological filmic discourse abounds in conceptual metaphors referring to ecology. Ecological concepts are quite difficult to capture, that is why filmmakers need to develop more complex metaphors capable of bringing to light ecological problems. These metaphors may emerge as a result of altering conventional conceptual metaphors by applying the techniques of 
extending, elaboration, combining and questioning. Respective modifications are effected in the synergy of disparate semiotic modes - verbal, visual, and / or aural. Different configurations of the modes result in highly individual construals.

Metaphorical meanings rendered verbally in the spoken mode occupy the main position in the hierarchy of modes in documentaries on ecology. It can be explained by the novelty of eco-friendly messages which need to be explicated in order to go down with the viewers. The visual mode, along with the verbal one or separately from it, can extend, drawing on new features in the source domain, or elaborate a metaphor, highlighting unconventional features of the source, as well as refer to a concept metonymically, creating a more vivid illustration of the target domain. The aural mode contributes to questioning a conventional conceptual metaphor by creating a contrasting tonality. Typically, the newly created contrasting tonality is supported by the verbal and visual modes.

The prospects for further research lie in bringing to light the role of metonymy in the process of metaphoric construal.

\section{References}

Forceville, Ch., Urios-Aparisi, E. (2009) Non-verbal and multimodal metaphor in a cognitive framework: agendas for research. Multimodal metaphor. Berlin-New York: Mouton de Gruyter, p. 19-44.

Inside Bill's brain: decoding Bill Gates, part 3 (2019). [Documentary].

Kövecses, Z. (2010a). Metaphor: A Practical Introduction. New York: Oxford University Press. Kövecses, Z. (2010b) A new look at metaphorical creativity. Cognitive Linguistics, 21(4), 663-697.

Kövecses, Z. (2015) Metaphor and Emergentism. In B. MacWhinney and W. O'Grady (Eds.). The Handbook of Language Emergence. Chichester, West Sussex: John Wiley \& Sons, Inc., 147-163.

Lakoff, G., Johnson, M. (1980) Metaphors We Live By. Chicago: Chicago University Press, $242 p$.

Lakoff, G., Johnson, M. (1999) Philosophy in the Flesh. New York: Basic Books.

Recycling Sham (2019). The Broken. [Documentary].

Sanford, D. R. (2012) Metaphors are Conceptual Schemata that are Emergent over Tokens of Use. Journal of Cognitive Science 13, 211-235.

Six degrees could change the world (2008). [Documentary].

Ushchyna V. From stance to identity: stancetaking in contemporary English risk discourse. Cognition, communication, discourse. 2020, 20: 73-91. DOI: 10.26565/2218-2926-2020-20-05 